\title{
Direct measurement of uranium in seawater by inductively coupled plasma mass spectrometry
}

Qiao, Jixin; Xu, Yihong

Published in:

Talanta

Link to article, DOI:

10.1016/j.talanta.2018.02.045

Publication date:

2018

Document Version

Peer reviewed version

Link back to DTU Orbit

Citation (APA):

Qiao, J., \& Xu, Y. (2018). Direct measurement of uranium in seawater by inductively coupled plasma mass spectrometry. Talanta, 183, 18-23. https://doi.org/10.1016/j.talanta.2018.02.045

\section{General rights}

Copyright and moral rights for the publications made accessible in the public portal are retained by the authors and/or other copyright owners and it is a condition of accessing publications that users recognise and abide by the legal requirements associated with these rights.

- Users may download and print one copy of any publication from the public portal for the purpose of private study or research.

- You may not further distribute the material or use it for any profit-making activity or commercial gain

- You may freely distribute the URL identifying the publication in the public portal

If you believe that this document breaches copyright please contact us providing details, and we will remove access to the work immediately and investigate your claim. 


\section{Author's Accepted Manuscript}

Direct measurement of uranium in seawater by inductively coupled plasma mass spectrometry

Jixin Qiao, Yihong Xu

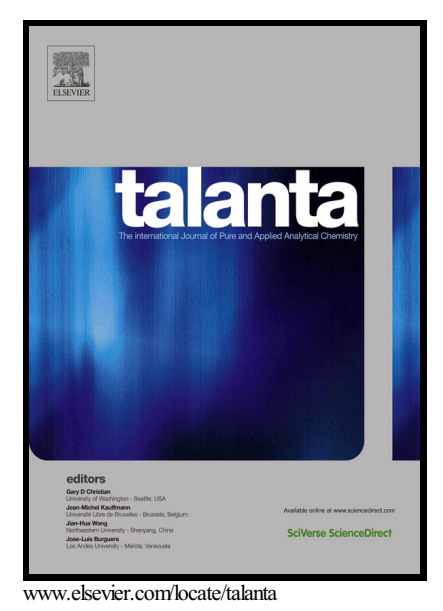

PII:

S0039-9140(18)30152-8

DOI: $\quad$ https://doi.org/10.1016/j.talanta.2018.02.045

Reference: TAL18364

To appear in: Talanta

Received date: 9 November 2017

Revised date: 8 February 2018

Accepted date: 10 February 2018

Cite this article as: Jixin Qiao and Yihong Xu, Direct measurement of uranium in seawater by inductively coupled plasma mass spectrometry, Talanta, https://doi.org/10.1016/j.talanta.2018.02.045

This is a PDF file of an unedited manuscript that has been accepted for publication. As a service to our customers we are providing this early version of the manuscript. The manuscript will undergo copyediting, typesetting, and review of the resulting galley proof before it is published in its final citable form. Please note that during the production process errors may be discovered which could affect the content, and all legal disclaimers that apply to the journal pertain. 


\title{
Direct measurement of uranium in seawater by
}

\section{inductively coupled plasma mass spectrometry}

\author{
Jixin Qiao ${ }^{a^{*}}$, Yihong Xu ${ }^{b^{*}}$ \\ ${ }^{a}$ Center of Nuclear Technologies, Technical University of Denmark, DTU Risø Campus, DK- \\ 4000 Roskilde, Denmark \\ ${ }^{b}$ The key Laboratory of Coastal and Island Development of Ministry of Education, School of \\ Geographic and Oceanographic Sciences, Nanjing University, Nanjing 210023, China
}

E-mail: jiqi@dtu.dk

yhxu@nju.edu.cn

${ }^{*}$ Corresponding author. Tel: 4546775367.

*Corresponding auhtor.

\begin{abstract}
A simple method for direct measurement of uranium $\left({ }^{238} \mathrm{U}\right)$ in seawater using triple quadrupole inductively coupled plasma mass spectrometry (ICP-MS) was established. The method provides a good analytical performance with respect to detection limit, accuracy, precision and sample
\end{abstract}


throughput. During the method development and application, several interesting facts were observed: 1) Comparison results for reference material using different quantitation approaches indicate that isotope dilution (using ${ }^{233} U$ ) is the most reliable to achieve accurate ${ }^{238} U$ measurement. The results obtained for direct ${ }^{238} \mathrm{U}$ measurement in 50 -fold diluted seawater samples $(\mathrm{n}=112)$ also underline the difference between isotope dilution and internal (or external) standardization. 2) Appropriate dilution of seawater is important to minimize the matrix effect on the ICP-MS measurement and 20-50 dilution is recommended for natural seawater samples. 3) The sensitivity of ICP-MS was observed to increase in the beginning of sample measurement, and then decrease with the continuous injection of samples, which is believed as a consequence of matrix effect from the seawater to the ionization efficiency in the plasma. 4) When measuring samples taken from large volume of seawater stored in immovable containers for relatively long period (i.e., several months), the uranium concentration and salinity data showed slightly increasing trends with the increase of water depth in the container. Therefore, cautions need to be paid in sampling representativeness when performing ${ }^{238} \mathrm{U}$ measurement for such long-term stored large volume samples.

Graphical abstract

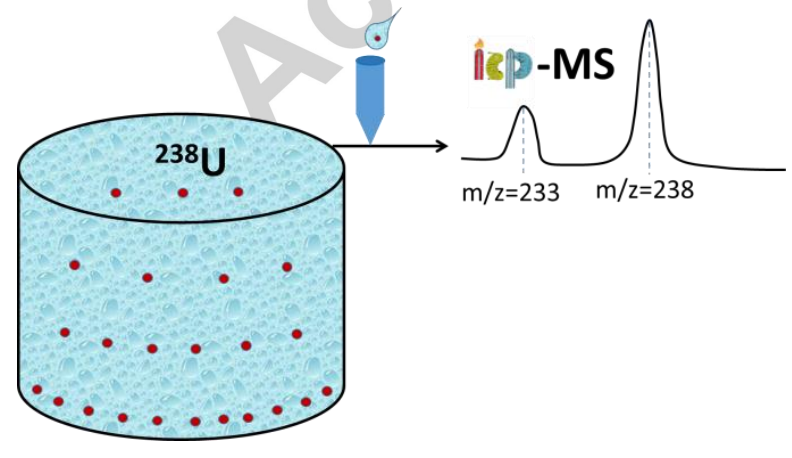

Keywords: ${ }^{238}$ U, seawater, ICP-MS, direct measurement 


\section{INTRODUCTION}

The ocean is the largest reservoir of natural uranium (4.5 billion metric ton,) in the world [1]. Concentration of uranium (with $99.2 \%$ of ${ }^{238} \mathrm{U}$ ) in seawater is typically $3.3 \mathrm{ug} / \mathrm{L}$, but can vary within 0.7-3.5 ug/L depending on location (open/marginal sea) and depth [2-4]. Elevated levels of uranium also occur in local marine environment due to uranium mining and processing, nuclear accidents, discharge of nuclear waste from reprocessing or decommissioning and dumping of nuclear spent fuel [5]. Determination of ${ }^{238} \mathrm{U}$ in seawater is of critical importance for several aspects including uranium recovery for nuclear energy production $[1,6-8]$, environmental monitoring and health physics [9-12] and geochemical/oceanic tracer studies [2,13-15].

There are a number of techniques available for the measurement of ${ }^{238} \mathrm{U}$ including alpha spectrometry [16], spectrophotometry [17-19], fluorescence spectrometry [10,20,21], voltammetry [22], neutron activation [23,24], X-ray absorption/fluorescence [25,26], inductively coupled plasma optical emission spectrometry (ICP-OES) [27,28]. However, these techniques generally have serious limitations due to relative high limits of detection, which involves lengthy sample pre-concentration with the possibility of sample contamination and/or elevated blank levels.

Inductively coupled plasma mass spectrometry (ICP-MS) is undoubtedly one of the fastestgrowing tracer element techniques available today, which has clear advantages in its multiisotope capability, high speed of analysis and low detection limits [29-33]. With the implementation of ICP-MS instruments, more and more researchers have reported the use of ICP-MS for the determination of ${ }^{238} \mathrm{U}$ in seawater [34-40]. Whereas most reported methods still 
associated with pre-concentration (typically involving co-precipitation) and chromatographic separation prior to the ICP-MS measurement, as such, suffered the disadvantages cited above.

To the best of our knowledge, method development for direct measurement of ${ }^{238} \mathrm{U}$ in natural seawater is limited. This is probably due to the fact that relatively high salt content in seawater will cause physical effects (sample orifice degradation and blockage) and chemical effects (matrix-induced interferences) to the ICP-MS measurement, which makes the quantitation analysis difficult. For example, a sample matrix of $0.1 \%$ dissolved solids content was reported to cause $15-80 \%$ signal suppression irrespective of sample type [41,42]. Roduskin and Ruth reported more than $50 \%$ signal loss for a 10 -fold dilution of NASS-4 seawater using a quadrupole instrument [43].

The aim of this study was to develop a rapid method for determination of ${ }^{238} \mathrm{U}$ in seawater based on the direct measurement by ICP-MS. To achieve this objective, several important aspects need to be taken account including optimization of the ICP-MS performance to meet the detection limit criteria, elimination of matrix affect, selection of calibration method for quantitation analysis to ensure the accuracy and precision, as well as the sample representativeness especially when small amount of sample $(<0.5 \mathrm{ml})$ is taken from a bulk sample for the direct analysis.

Therefore, in this work systematic studies were carried out to evaluate the effect of abovementioned parameters on the analytical performance, including instrument operational condition, quantitation approaches (internal standardization using ${ }^{115} \mathrm{In}$, isotope dilution using ${ }^{233} \mathrm{U}$ and external standardization), dilution factor, sample matrix effect and sample representativeness. Analytical results were demonstrated and discussed in detail to select the optimum approach for rapid and reliable analysis of ${ }^{238} \mathrm{U}$ in seawater. 


\section{EXPERIMENTAL}

\section{Standards, reagents and samples}

An in-house ${ }^{233} \mathrm{U}$ standard solution $\left(0.594 \mathrm{ppb}\right.$ in $\left.2 \mathrm{~mol} / \mathrm{L} \mathrm{HNO}_{3}\right)$ was used for the isotopic dilution measurement of ${ }^{238} \mathrm{U}$. Standard solutions of uranium and indium were diluted to different levels from the corresponding commercially available standards $(1.000 \mathrm{~g} / \mathrm{L}$ in $2 \mathrm{~mol} / \mathrm{L}$ $\mathrm{HNO}_{3}$, Scientific Standards) and used for calibration purposes. Concentrated $\mathrm{HNO}_{3}$ (analytical reagent grade) was further purified by distillation. All the reagents used in the experiment were prepared using ultra-pure water $(18 \mathrm{M} \Omega \cdot \mathrm{cm})$. Seawater samples collected from the Baltic Sea and Greenland Sea during the period of 2013-2015 were used for the method performance evaluation. Two large volume (600 L) of seawater samples, Roskilde SWT and Greenland SWT, were collected in 2012 from Roskilde Fjord $\left(55.68^{\circ} \mathrm{N}, 12.08^{\circ} \mathrm{E}\right)$, Denmark and North-eastern coast of Greenland $\left(71.99^{\circ} \mathrm{N}, 18.05^{\circ} \mathrm{W}\right)$, respectively, which were used for the sample representativeness investigation in this work. These two large seawater samples were kept immovably for 6 months, thereafter four sub-samples were taken from each sample at different depths $(0,15,35$ and $50 \mathrm{~cm}$, respectively). These eight subsamples were further splited and treated with and without filtration prior to the measurements of ${ }^{238} \mathrm{U}$ and salinity.

\section{Measurement of uranium with ICP-MS}

In the direct ${ }^{238} \mathrm{U}$ ICP-MS analysis, seawater samples were prepared in accordance with the quantitation approach applied. For the isotope dilution approach, $100-500 \mu \mathrm{L}$ of pre-filtered seawater sample was pipetted into a $10 \mathrm{~mL}$ polystyrene centrifuge tube and diluted to $5 \mathrm{~mL}$ with $0.5 \mathrm{~mol} / \mathrm{L} \mathrm{HNO}_{3} .100 \mu \mathrm{L}$ of ${ }^{233} \mathrm{U}$ standard solution was spiked to each sample to a final concentration of 5-6 ppt. For internal standardization approach, ${ }^{115}$ In was used as an internal standard, whereby $100-500 \mu \mathrm{L}$ of pre-filtered seawater sample was diluted to $5 \mathrm{~mL}$ with $1 \mathrm{ppb}$ 
${ }^{115} \mathrm{In}-0.5 \mathrm{~mol} / \mathrm{L} \mathrm{HNO}_{3}$ solution. For the external standardization approach, $100-500 \mu \mathrm{L}$ of prefiltered seawater sample was diluted to $5 \mathrm{~mL}$ with $0.5 \mathrm{~mol} / \mathrm{L} \mathrm{HNO}_{3}$ and only ${ }^{238} \mathrm{U}$ was measured by the ICP-MS instrument.

The measurement throughout the work was carried with a triple quadrupole inductively coupled mass spectrometry, Agilent 8800 ICP-QQQ (Agilent Technologies). A standard introduction system consisted of MicroMist nebulizer and Scott-type double pass spray chamber, together with $\mathrm{Ni}$ sampler cone, Ni skimmer cone and $\mathrm{x}$-lens were used. Typical sensitivity of the instrument is about $600-650$ cps per ppt of ${ }^{238} \mathrm{U}$. The regression analysis of standard solution confirmed a linear correlation over the range of $0.01 \mathrm{ppb}$ to $100 \mathrm{ppb}$ for ${ }^{238} \mathrm{U}$. The uptake of the sample was performed at a flow rate of $20 \mu \mathrm{L} / \mathrm{min}$ with an AS X-520 auto-sampler (CETAC Technologies, USA) connected to a standard peristaltic pump equipped in the ICP-QQQ instrument.

\section{Quantitation analysis and calculation of detection limit}

Three approaches were applied for the quantitation analysis, including internal standardization, isotope dilution and external standardization. The calibration was accomplished by using a blank and three standard solutions with ${ }^{238} \mathrm{U}$ concentrations of $0.1,0.2$ and $1 \mathrm{ppb}$, respectively. The matrix of blank/standard solutions were $1 \mathrm{ppb}$ In- $0.5 \mathrm{~mol} / \mathrm{L} \mathrm{HNO}_{3}$ for the internal and external standardization approaches, and $0.5 \mathrm{~mol} / \mathrm{L} \mathrm{HNO}_{3}$ for the isotope dilution approach. The blank and standard solutions were run before and after every 10 samples measurement to allow a correction for intensity drift. The blank signal was subtracted from both the standard and the sample signals.

In the internal standardization, the ICP-MS measurement efficiency $(E)$ for each sample was calculated as the ratio between ${ }^{115}$ In signal in the sample and in the standard, thus to calibrate the 
actual count rate $(A C R)$ of ${ }^{238} \mathrm{U}\left(A C R=C R / E\right.$, where $C R$ is the measured count rate of $\left.{ }^{238} \mathrm{U}\right)$. The ${ }^{238} \mathrm{U}$ standard solution with concentration (mostly $0.1 \mathrm{ppb}$ ) close to the sample was chosen to be a reference to do the linear regression for calculating the ${ }^{238} \mathrm{U}$ concertation in the sample. For the isotope dilution, the ${ }^{238} \mathrm{U}$ and ${ }^{233} \mathrm{U}$ signals in the ICP-MS measurement were used to calculate the massic isotope ratio $\left(R_{U-238 / U-233}\right)$ between ${ }^{238} \mathrm{U}$ and ${ }^{233} \mathrm{U}$. As known amount of ${ }^{233} \mathrm{U}$ was spiked into each sample, the absolute concentration $\left(C_{U-238}\right)$ of ${ }^{238} \mathrm{U}$ in the sample can be calculated as $C_{U-238}=C_{233 U^{*}} R_{U-238 / U-233}$. In the external standardization, a simple linear regression was employed by plotting the signals of the three standard solutions (y-axis) versus their corresponding ${ }^{238} \mathrm{U}$ concentrations (x-axis), thus to calculate the ${ }^{238} \mathrm{U}$ concertation in each real sample.

The instrumental limit of detection (LOD) was calculated as 3 times of standard deviation $(3 * \mathrm{SD})$ of blank solution $(\mathrm{n}=10)$, namely, $0.5 \mathrm{~mol} / \mathrm{L} \mathrm{HNO}_{3}$ or $1 \mathrm{ppb} \mathrm{In}-0.5 \mathrm{~mol} / \mathrm{L} \mathrm{HNO}_{3}$. The method detection limit (MDL) was calculated as $3 * \mathrm{SD} * \mathrm{~d}$, where $\mathrm{d}$ is the dilution factor for the sample, therefore the MDL will be $30 * \mathrm{SD}, 60 * \mathrm{SD}$ and $150 * \mathrm{SD}$, for a 10-time, 20-time and 50time diluted sample, respectively.

\section{RESULTS AND DISCUSSION}

\section{Operational conditions and analytical performance of the ICP-QQQ instrument}

The operational condition was optimized based on tuning of different parameters for the ICPQQQ instrument to achieve sufficiently high sensitivity and stability for the measurement. The optimized condition for the ICP-QQQ instrumental operation is listed in Table 1. The ICP-QQQ was operated without the use of reaction cell, i.e., $\mathrm{M} 1=\mathrm{M} 2=238$. Monitored masses were typically $\mathrm{m} / \mathrm{z}=115,232,233238$ for ${ }^{115} \mathrm{In},{ }^{232} \mathrm{Th},{ }^{233} \mathrm{U}$ and ${ }^{238} \mathrm{U}$ with integrated measurement time (integrated time $=$ dwell time $\times$ sweeps + stabilization time between sweeps) of $0.1 \mathrm{~s}, 0.1 \mathrm{~s}, 3 \mathrm{~s}$ and 
$3 \mathrm{~s}$, respectively. The reason for monitoring ${ }^{232} \mathrm{Th}$ is to ensure that no interference of thorium hydride ${ }^{232} \mathrm{Th}^{1} \mathrm{H}$ at $\mathrm{m} / \mathrm{z}=233$ would occur for ${ }^{233} \mathrm{U}$ measurement. It was observed that the increase of integrated time for each analyte would facilitate a stable instrumental condition, thus provide improved repeatability for the measurement.

On the other hand, integrated time should also be compromised with the sample throughput and operational cost to achieve a rapid and cost-effective measurement. In principle, the more sweeps the better statistic of the measurement, however, more stabilization time ('dead time' for the detector) will be needed between each sweep, and therefore the sweeps were optimized to be 300 in this work. Under the operational condition summarized in Table, 1, a good repeatability with a relative standard deviation value (RSD) of about 3\% ( $\mathrm{n}=6)$ was achieved from analysis of a 50-time diluted seawater sample containing $3.4 \mathrm{ppb}$ of uranium. The total turnover time for each sample analysis including washing (45s), sample uptake (45s) and measurement (62 s) is about 2-3 minutes; considering all other times involved in sample preparation (dilution) and calibration, a sample throughput of 12 sample/h can be achieved.

The calculated results for LODs and MDLs for ${ }^{238} \mathrm{U}$ in different quantitation approaches indicate that both LODs and MDLs were blank limited. The LOD and MDLs are 5-folder lower when using $0.5 \mathrm{~mol} / \mathrm{L} \mathrm{HNO}_{3}$ as the blank solution $(\mathrm{LOD}=0.11 \mathrm{ppt}$ and $\mathrm{MDL}=1.14-5.68 \mathrm{ppt}$ for 10-50 times diluted sample) than the ones (using $1 \mathrm{ppb}$ In- $0.5 \mathrm{~mol} / \mathrm{L} \mathrm{HNO}_{3}$ as the blank solution $\mathrm{LOD}=0.68 \mathrm{ppt}$ and $\mathrm{MDL}=6.77-33.85 \mathrm{ppt}$ for $10-50$ times diluted sample). From the average signal measured at $\mathrm{m} / \mathrm{z}=238$ for both blank solutions $\left(320 \mathrm{cps}\right.$ in $0.5 \mathrm{HNO}_{3}$ solution versus 1223 cps in $1 \mathrm{ppb}$ In- $0.5 \mathrm{~mol} / \mathrm{L} \mathrm{HNO}_{3}$ ), we could confirm the relatively high ${ }^{238} \mathrm{U}$ contribution from the indium standard solution into the blank. Nonetheless, all the LODs and MDLs obtained above are at least two orders of magnitude lower than typical ${ }^{238} \mathrm{U}$ concentration $(3 \mathrm{ppb})$ in open 
seawater, indicating the ICP-QQQ instrument provides sufficient sensitivity for real seawater sample analysis.

\section{Matrix effect on the sensitivity of the ICP-QQQ instrument}

Figure 1 indicates the variation of ${ }^{238} \mathrm{U}$ sensitivity with the ICP-QQQ measurement time for seawater samples after 50 -time dilution. It can be seen that the sensitivity of ${ }^{238} \mathrm{U}$ increases by $15 \%$ (from 0.6 to $0.7 \mathrm{cps} / \mathrm{ppq}$ ) in the first hour of measurement. Afterwards, the sensitivity continuously dropped with the measurement time and reached to about $0.5 \mathrm{cps} / \mathrm{ppq}$ (corresponding to $30 \%$ signal suppression) when the ICP-QQQ operational time reached to 4 hours. This variation is very likely due to the matrix effect of seawater samples. In open seawater, the typical salinity is around $35 \%$ with $\mathrm{Na}^{+}(11 \mathrm{ppm}), \mathrm{Mg}^{2+}(1.2 \mathrm{ppm}), \mathrm{Ca}^{2+}(0.4 \mathrm{ppm})$ and $\mathrm{K}^{+}(0.4 \mathrm{ppm})$ as the major cations, even after 50 times dilution, the total concentration of $\mathrm{Na}$, $\mathrm{Mg}, \mathrm{Ca}$ and $\mathrm{K}$ elements is still as high as $0.3 \mathrm{ppm}$ [44].

The signal enhancement in initial measurement might be attributed to the increased collisional rate due to the existence of easily ionized elements (primarily $\mathrm{Na}, \mathrm{Mg}, \mathrm{Ca}$ and $\mathrm{K}$ ) $[45,46]$. However, with the continuous injection of samples, a suppression of ionisation occurred. This could be a consequence of the deposition of dissolved solids in seawater, which slowly plug or clog the sample introduction pathway (nebuliser, torch, sampler and skimmer cone orifices). Similar signal enhancement and suppression phenomena induced by the concomitant elements ( $\mathrm{Na}, \mathrm{K}, \mathrm{Cs}, \mathrm{Mg}$ and $\mathrm{Ca}$ ) have been reported in previous studies for several analytes ( $\mathrm{V}, \mathrm{Cr}, \mathrm{Mn}$, $\mathrm{Ni}, \mathrm{Co}, \mathrm{Cu}, \mathrm{Zn}, \mathrm{Cd}$ and $\mathrm{Pb}$ ) [46], which is in good agreement with our observation.

Practically, to obtain a relatively stable measurement condition, it is recommended to 'precondition' the ICP-MS instrument by running a few real samples (without using the data) prior to the real measurement. Regular cleaning the system (especially sampler and skimmer cones) and 
retuning the instrumental parameters is necessary to maintain the optimal operational condition, especially when observing a significant signal drop after continuously measuring a number of real seawater samples.

\section{Quantitation analysis for ${ }^{238} \mathrm{U}$ ICP-MS measurement}

To test the analytical performance of the ICP-MS measurements for ${ }^{238} \mathrm{U}$ with different calibration approaches (internal standardization, isotope dilution and external calibration), a series of studies were carried out on 10-50 times dilution of IAEA-381 seawater [47]. There are also other approaches for the quantitation of ${ }^{238} \mathrm{U}$ can be used, for example, standard addition and addition calibration. However, both approaches are rather tedious $[38,48]$, therefore were not applied in this work.

From Table 2 it can be seen that, higher relative bias are observed for values calculated using either internal standardization $\left({ }^{115} \mathrm{In}\right)$ or external standardization compared to isotope dilution approach. In the external standardization approach, the dilution factor affects significantly the analytical accuracy and the relatively bias changed from $1.6 \%$ to $-31.7 \%$, when the dilution factor decreased from 50 to 10 . This reflects the prominent matrix effect to the ionization efficiency when insufficiently diluted seawater was injected into the plasma. Comparing to the external standardization, the isotope dilution and internal standardization approaches are less sensitive to the dilution factor, but still, the highest relative bias occurred for samples with the least dilution (10 times) in both cases. The slightly increased relative bias in internal standardization approach probably related to the relatively high background level in the $1 \mathrm{ppb}$ In$0.5 \mathrm{~mol} / \mathrm{L} \mathrm{HNO}_{3}$ blank solution. Among these three quantitation approaches, the isotope dilution indicates the most stabilized accuracy for 20-50 folders diluted seawater, which is selected as the optimal approach in this work. Another advantage of isotopic dilution approach is that no 
calibration curve is needed, since it is a relative method and the ${ }^{238} \mathrm{U}$ results only related to the ratio of ${ }^{238} \mathrm{U} /{ }^{233} \mathrm{U}$ signal from the ICP-MS and ${ }^{233} \mathrm{U}$ spiked in the samples. Whereas for the internal and external standardization approaches, careful linear regression analysis have to be carried out each time by selecting appropriate concentrations of standard solution to ensure the sample signal to be in central zone of calibration curve.

Based on the measurement of 112 Baltic and Greenlandic seawater samples with ${ }^{238} \mathrm{U}$ ranging within 0.1-3.7 ppb, the correlation between the ${ }^{238} \mathrm{U}$ concentration calculated using internal standardization (y) and isotope dilution ( $\mathrm{x}$ ) is $\mathrm{y}=1.168 \mathrm{x}$ (see Figure 2). This means there is averagely $16.8 \%$ relative bias for the values obtained by internal standardization comparing to isotope dilution, which potentially suggests that ${ }^{115}$ In may not be an ideal internal standard for ${ }^{238} \mathrm{U}$. The following explanations are possible for this result: 1) mass discrimination effect due to the large difference in mass number between ${ }^{115} \mathrm{In}(\mathrm{m} / \mathrm{z}=115)$ and ${ }^{238} \mathrm{U}(\mathrm{m} / \mathrm{z}=238)$, which is confirmed by several studies suggesting the important of close match in terms of mass number of analyte and internal standard to the analytical precision and accuracy $[45,49,50]$; 2) differences between ${ }^{115} \mathrm{In}$ and ${ }^{238} \mathrm{U}$ in signal enhancement or suppression caused by concomitant matrix elements [46]; 3) different 'build-up' memory effect in the ICP-MS system due to their different chemical properties.

Besides ${ }^{115}$ In, serval other internal standards have been reported for ${ }^{238} \mathrm{U}$ analysis, including ${ }^{103} \mathrm{Rh},{ }^{159} \mathrm{~Tb},{ }^{165} \mathrm{Ho},{ }^{209} \mathrm{Bi}$ and ${ }^{205} \mathrm{Tl}[37,40,51]$. Promising results have been reported when ${ }^{103} \mathrm{Rh}$ was used as an internal standard for uranium measurement in tap water [40]. This is in contrast to the theory of mass discrimination effect since ${ }^{103} \mathrm{Rh}$ and ${ }^{238} \mathrm{U}$ have rather larger mass difference than that between ${ }^{115}$ In and ${ }^{238} \mathrm{U}$. However, this mass discrimination maybe less significant for fresh water samples with low matrix content compare to seawater. Igarashi et al. [51] compared 
several internal standards (including ${ }^{115} \mathrm{In}$ ) for ${ }^{238} \mathrm{U}$ determination in biological samples, where ${ }^{115} \mathrm{In}$ indicated the most significant signal drift from ${ }^{238} \mathrm{U}$, in contrast, ${ }^{209} \mathrm{Bi}$ and ${ }^{205} \mathrm{Tl}$ were selected as optimal internal standards for ${ }^{238} \mathrm{U}$.

The correlation (Figure 2) between the ${ }^{238} \mathrm{U}$ concentration calculated by external standardization $(\mathrm{y})$ and isotope dilution $(\mathrm{x})$ is $\mathrm{y}=1.033 \mathrm{x}$, indicating smaller deviation (3.3\%) between the values calculated using a simple linear regression and the isotope dilution. This implies that external standardization could be applied for seawater samples with sufficient dilution (e.g., 50 times), especially in the case that ${ }^{233} \mathrm{U}$ spike is not available for the measurement. Nevertheless, it should be noted that external standardization still could produce erroneous results because of the matrix-induced interferences, since in some extreme cases (e.g., seawater with high organic matter content) it is difficult to closely match the matrix of the standards with the samples.

\section{Representativeness of the sample for ${ }^{238} \mathrm{U}$ measurement}

In the experiment, an interesting phoneme reflecting the impact of sample representativeness on the ${ }^{238} \mathrm{U}$ (and salinity) results was observed. After kept Roskilde SWT and Greenland SWT immovably for 6 months, four sub-samples were taken from each sample at different depths. These eight subsamples were treated with and without filtration to check whether uranium was attached to the small particles during the storage. As indicated in Figure 3, the overall results for salinity and ${ }^{238} \mathrm{U}$ are comparable between filtered and unfiltered sub-samples, which in line with our observation in practice that negligible amount of particles was obtained after the filtration for all sub-samples.

Salinity data indicate a general increasing trend with the increase of depth where the sample was taken. ${ }^{238} \mathrm{U}$ concentration in the saline seawater (Greenland SWT) from an open sea also 
increases with the increase of sample depth, except a slight fluctuation occurred in the second layer $(15 \mathrm{~cm})$, which probably due to the disturbance and water movement during the subsample collection. For the brackish seawater (Roskilde SWT) from a shallow fjord, the ${ }^{238} \mathrm{U}$ concentration is decreasing slightly for the bottom layer. This might be a consequence of precipitation of ${ }^{238} \mathrm{U}$ after being reduced from $\mathrm{U}(\mathrm{VI})$ to $\mathrm{U}(\mathrm{IV})$ due to the depletion of oxygen in the water, since large areas of the container were covered by self-growing fungus after 6-months storage.

Even considering the measurement uncertainties $(<10 \%)$, the differences in salinity and ${ }^{238} \mathrm{U}$ concentration between the surface and bottom layer is still notable (24\% and $11 \%$ for salinity in the Roskilde SWT and Greenland SWT, respectively, and $16 \%$ for ${ }^{238} \mathrm{U}$ in the Greenland SWT). This probably can be explained by the fact that with temperature change during the sample storage, pure water molecular (containing neither uranium and nor salts) maybe evaporated and then condensed on the wall of the container which finally dripping or flowing along the wall to the seawater surface, thus the ${ }^{238} \mathrm{U}$ concentration and salinity were diluted. The increased ${ }^{238} \mathrm{U}$ concentration and salinity could partly be a build-up consequence of this long-term evaporationcondensation process; it could also be related to the thermodynamic movement of molecular which requires more in-depth investigation to reveal the detailed mechanism. Nevertheless, our overall observations suggest whenever taking small aliquots from large volume of water samples stored in immovable containers for relatively long periods, vigorous mechanical mixing prior to the sampling is necessary to ensure the homogeneity of the sample and thus the representativeness of the analytical results.

CONCLUSIONS AND PERSPECTIVES 
A simple method was established and successfully applied for direct measurement of uranium $\left.{ }^{238} \mathrm{U}\right)$ in seawater. The method provides a rapid analysis of ${ }^{238} \mathrm{U}$ with sample throughput of 12 sample/h, a limit of detection of $0.1 \mathrm{ppt}$ and good repeatability with a relative standard deviation (RSD) of about $3 \%(n=6) .20-50$ time dilution for typical seawater samples combining with isotope dilution for quantitation analysis is recommended in the proposed method for achieving reliable ${ }^{238} \mathrm{U}$ concentration measurement. While confirming the applicability of the ICP-MSbased method to obtain fast and accurate information on ${ }^{238} \mathrm{U}$ concentrations in seawater, the proposed method can be easily applied for any other type of water samples. The analytical merit of direct measurement of ${ }^{238} \mathrm{U}$ is not only providing an effective analysis for ${ }^{238} \mathrm{U}$ concentration, in many cases involving determination of minor uranium isotopes (e.g., ${ }^{236} \mathrm{U},{ }^{234} \mathrm{U},{ }^{235} \mathrm{U}$ ), the directly measurable ${ }^{238} \mathrm{U}$ (before and after the chemical separation) can also service as an intrinsic chemical yield tracer for these minor uranium isotopes, thus no addition of high-purity chemical yield tracer (e.g., ${ }^{232} \mathrm{U}$ or ${ }^{233} \mathrm{U}$ ) is need. Differentiated ${ }^{238} \mathrm{U}$ concentrations were observed in subsamples taken at different layers from bulk seawaters stored for 6 months, triggering our awareness in the sample representativeness when handling large volume water samples after long periods of storage.

\section{ACKNOWLEDGEMENT}

J. Qiao is grateful to the fully support from colleagues in Radioecology Section at Hevesy Laboratory, Center for Nuclear Technologies, Technical University of Denmark. Y. Xu thanks to the support from Natural Science Foundation of Jiangsu Province (BK20150578) and the National Natural Science Foundation of China (No. 41501286). 


\section{References}

[1] A. Favre-reguillon, G. Lebuzit, J. Foos, A. Guy, M. Lemaire, Selective concentration of uranium from seawater by nanofiltration, Ind. Eng. Chem. Res. 42 (2003) 5900-5904. doi:10.1021/ie030157a.

[2] J. Qiao, P. Steier, S. Nielsen, X. Hou, P. Roos, R. Golser, Anthropogenic 236U in Danish seawater: global fallout versus reprocessing discharge, Environ. Sci. Technol. 51 (2017) 6867-6876. doi:10.1021/acs.est.7b00504.

[3] S.A. Owens, K.O. Buesseler, K.W.W. Sims, Re-evaluating the U-238-salinity relationship in seawater: Implications for the U-238-Th-234 disequilibrium method, Mar. Chem. 127 (2011) 3139. doi:10.1016/j.marchem.2011.07.005.

[4] T.L. KU, K.G. Knauss, G.G. Mathieu, Uranium in open ocean - concentration and isotopic composition, Deep. Res. 24 (1977) 1005-1017.

[5] H.B.L. Pettersson, Dispersion of long-lived radionuclides from uranium mining, milling and fuel fabrication facilities. Environmental studies and radiological assessment, Lund University, 1990.

[6] R. Djogic, L. Sipos, M. Branica, Characterization of uranium (VI) in seawater, Limnol. Oceanogr. 31 (1986) 1122-1131.

[7] P.G. Jaison, V.M. Telmore, P. Kumar, S.K. Aggarwal, Determination of uranium in seawater samples by liquid chromatography using mandelic acid as a complexing agent, J. Chromatogr. Sci. 49 (2011) 657-664.

[8] K. Oguma, T. Suzuki, K. Saito, Determination of uranium in seawater by flow-injection preconcentration on dodecylamidoxime-impregnated resin and spectrophotometric detection, Talanta. 84 (2011) 1209-1214. 
[9] C.M. Hutchins, J.G. Panther, P.R. Teasdale, F. Wang, R.R. Stewart, W.W. Bennett, H. Zhao, Talanta Evaluation of a titanium dioxide-based DGT technique for measuring inorganic uranium species in fresh and marine waters, Talanta. 97 (2012) 550-556. doi:10.1016/j.talanta.2012.05.012.

[10] S.A. Kumar, N.S. Shenoy, S. Pandey, S. Sounderajan, G. Venkateswaran, Direct determination of uranium in seawater by laser fluorimetry, Talanta. 77 (2008) 422-426. doi:10.1016/j.talanta.2008.07.002.

[11] V. V Kuznetsov, S. V Zemyatova, K.A. Kornev, Automated determination of uranium (VI) in seawater using on-line preconcentration by coprecipitation, J. Anal. Chem. 69 (2014) 105-110. doi:10.1134/S106193481312006X.

[12] S. Maity, S.K. Sahu, G.G. Pandit, Standardization of solvent extraction procedure for determination of uranium in seawater, J. Radioanal. Nucl. Chem. 303 (2015) 33-37. doi:10.1007/s10967-014-3410-9.

[13] K. Hirose, Y. Sugimura, Chemical speciation of particulate uranium in seawater, J. Radioanal. Nucl. Chem. 149 (1991) 83-96.

[14] N. Casacuberta, P. Masqué, G. Henderson, M. Rutgers van-der-Loeff, D. Bauch, C. Vockenhuber, A. Daraoui, C. Walther, H.A. Synal, M. Christl, First 236U data from the Arctic Ocean and use of 236U/238U and 129I/236U as a new dual tracer, Earth Planet. Sci. Lett. 440 (2016) 127-134. doi:10.1016/j.epsl.2016.02.020.

[15] J.M. Rolison, C.H. Stirling, R. Middag, M.J.A. Rijkenberg, Uranium stable isotope fractionation in the Black Sea : Modern calibration of the 238U / 235U paleo-redox proxy, Geochim. Cosmochim. Acta. 203 (2017) 69-88. doi:10.1016/j.gca.2016.12.014.

[16] N. V Suc, T.T. Bich, Determination of $234 \mathrm{U}$ and $238 \mathrm{U}$ in seawater samples by alpha spectrometry after concentration of U(VI) onto hydrotalcite and co-precipitation with LaF3, Radiochim. Acta. 
101 (2013) 621-624. doi:10.1524/ract.2013.2082.

[17] P.G. Jaison, V.M. Telmore, P. Kumar, S.K. Aggarwal, A RP-HPLC method using $\alpha$-hydroxy isobutyric acid for preconcentration and determination of uranium in seawater, J. Chromatogr. Sci. 49 (2011) 72-78.

[18] M. Konstantinou, I. Pashalidis, Speciation and spectrophotometric determination of uranium in seawater, Medierranean Mar. Sci. 5 (2004) 55-60.

[19] R. Kuroda, K. Oguma, N. Mukai, M. Iwamoto, Anion-exchange enrichment and spectrophotometric determination of uranium in sea-water, Talanta. 34 (1987) 433-434.

[20] D. Huang, F. Deng, J. He, T. Yu, Determination of uranium in seawater, biological samples and sediments using laser induced fluorescence spectrometry, J. Radioanal. Nucl. Chem. 307 (2016) 1359-1363. doi:10.1007/s10967-015-4250-y.

[21] J. Korkisch, I. Steefan, Determination of uranium in sea water after anion-exchange separation, Anal. Chim. Acta. 77 (1975) 312-314.

[22] L. Zhang, C. Wang, H. Tang, L. Wang, Y. Liu, Y. Zhao, Z. Chai, W. Shi, Rapid determination of uranium in water samples by adsorptive cathodic stripping voltammetry using a tin-bismuth alloy electrode, Electrochim. Acta. 174 (2015) 925-932. doi:10.1016/j.electacta.2015.06.087.

[23] X.L. Hou, Study on chemical species of inorganic elements in some marine algae by neutron activation analysis combined with chemical and biochemical separation techniques, J. Radioanal. Nucl. Chem. 242 (1999) 49-61.

[24] A.R. Byrne, L. Benedik, Determination of uranium and thorium radioisotopes using instrumental neutron activation analysis, Inorg. Anal. Chem. 69 (1997) 996-999.

[25] M. Maloubier, P.L. Solari, P. Moisy, M. Monfort, C. Den Auwer, C. Moulin, XAS and TRLIF 
spectroscopy of uranium and neputium in seawater, Dalt. Trans. 44 (2015) 5417-5427. doi:10.1039/c4dt03547j.

[26] N.L. Misra, S. Dhara, K.D.S. Mudher, Uranium determination in seawater by total reflection Xray fluorescence spectrometry, Spectrochim. Acta B. 61 (2006) 1166-1169. doi:10.1016/j.sab.2006.05.002.

[27] G. Daneshvar, A. Jabbari, Y. Yamini, D. Paki, Determination of uranium and thorium in natural waters by ICP-OES after on-line solid phase extraction and preconcentration in the presence of 2,3-dihydro-9,10-dihydroxy-1,4-antracenedion, J. Anal. Chem. 64 (2009) 602-608. doi:10.1134/S1061934809060112.

[28] D.S. Zamzow, D.P. Baidwin, S.J. Weeks, S.J. Bajlc, A.P.D. Siiva, In situ determination of ranium in soil by laser ablation-inductively coupled plasma atomic emission spectrometry, Environ. Sci. Technol. 28 (1994) 352-358.

[29] J. Zheng, M. Yamada, Inductively coupled plasma-sector field mass spectrometry with a highefficiency sample introduction system for the determination of Pu isotopes in settling particles at femtogram levels, Talanta. 69 (2006) 1246-1253. doi:10.1016/j.talanta.2005.12.047.

[30] J. Zheng, M. Yamada, Isotope dilution sector-field inductively coupled plasma mass spectrometry combined with extraction chromatography for rapid determination of Am-241 in marine sediment samples: A case study in Sagami Bay, Japan, J. Oceanogr. 64 (2008) 541-550.

[31] P. Lindahl, M. Keith-Roach, P. Worsfold, M.-S. Choi, H.-S. Shin, S.-H. Lee, Ultra-trace determination of plutonium in marine samples using multi-collector inductively coupled plasma mass spectrometry, Anal. Chim. Acta. 671 (2010) 61-69. doi:10.1016/j.aca.2010.05.012.

[32] J. Zheng, K. Tagami, S. Homma-Takeda, W. Bu, The key role of atomic spectrometry in radiation protection, J. Anal. At. Spectrom. 28 (2013) 1676. doi:10.1039/c3ja50217a. 
[33] B.C. Russell, I.W. Croudace, P.E. Warwick, Determination of 135Cs and 137Cs in environmental samples: A review., Anal. Chim. Acta. 890 (2015) 7-20. doi:10.1016/j.aca.2015.06.037.

[34] J.R. Wood, G.A. Gill, L. Kuo, J.E. Strivens, K. Choe, Comparison of analytical methods for the determination of uranium in seawater using inductively coupled plasma mass spectrometry, Ind. Eng. Chem. Res. 55 (2016) 4344-4350. doi:10.1021/acs.iecr.5b03680.

[35] S. Dadfarnia, C.W. McLeod, On-line trace enrichment and determination of uranium in waters by flow injection inductively coupled plasma mass spectrometry, Appl. Spectrosc. 48 (1994) 13311336.

[36] D. Beauchemin, S.S. Berman, Determination of trace metals in reference water standards by inductively coupled plasma mass spectrometry with on-line preconcentration, Anal. Chem. 61 (1989) 1857-1862.

[37] J.B. Truscott, L. Bromley, P. Jones, E.H. Evans, B. Fairman, Determination of natural uranium and thorium in environmental samples by ETV-ICP-MS after matrix removal by on-line solid phase extraction, J. Anal. At. Spectrom. 14 (1999) 627-631.

[38] C.L. Chou, J.D. Moffatt, A simple co-precipitation inductively coupled plasma mass spectrometric method for the determination of uranium in seawater, Fresenius' J. Anal. Chem. 368 (2000) 59-61. doi:10.1007/s002160000518.

[39] E.R. Unsworth, J.M. Cook, S.J. Hill, Determination of uranium and thorium in natural waters with a high matrix concentration using solid-phase extraction inductively coupled plasma mass spectrometry, Anal. Chim. Acta. 442 (2001) 141-146. doi:10.1016/S0003-2670(01)01138-2.

[40] M. El Himri, A. Pastor, M. de la Guardia, Determination of uranium in tap water by ICP-MS, Fresenius J. Anal. Chem. 367 (2000) 151-156. 
[41] J.A. Olivares, R.S. Houk, Suppression of analyte signal by various concomitant salts in inductively coupled plasma mass spectrometry, Anal. Chem. 58 (1986) 20-25. doi:10.1021/ac00292a008.

[42] A.L. Gray, A.R. Gate, Indictively coupled plasma source mass spectrometry using continuum flow ion extraction, Analyst. 108 (1983) 1033-1050.

[43] I. Rodushkin, T. Ruth, Determination of trace metals in estuarine and sea-water reference materials by high resolution inductively coupled plasma mass spectrometry, J. Anal. At. Spectrom. 12 (1997) 1181-1185.

[44] K.K. Turekian, Oceans, Prentice-Hall, Englewood Cliffs, N.J., 1968.

[45] F. Vanhaecke, H. Vanhoe, R. Dams, C. Vandecasteele, The use of internal standards in ICP-MS, Talanta. 39 (1992) 737-742.

[46] D. Beauchemin, J.W. Mclaren, S.S. Herman, Study of the effects of concomitant elements in inductively coupled plasmamass spectrometry, Spectrochim. Acta. 42B (1987) 467-490. doi:10.1016/0584-8547(87)80024-1.

[47] P.P. Povinec, C. Badie, A. Baeza, G. Barci-Funel, T.D. Bergan, R. Bojanowski, W. Burnett, J. Eikenberg, L.K. Fifield, V. Serradell, J. Gastaud, I. Goroncy, J. Herrmann, M.A.C. Hotchkis, T.K. Ikaheimonen, E. Jakobson, J. Kalimbadjan, J.J. La Rosa, S.H. Lee, L.L.W. Kwong, W.M. Lueng, S.P. Nielsen, A. Noureddine, M.K. Pham, J.-N. Rohou, J.A. Sanchez-Cabeza, J. Suomela, M. Suplinska, E. Wyse, Certified reference material for radionuclides in seawater IAEA-381 (Irish Sea Water), J. Radioanal. Nucl. Chem. 251 (2002) 369-374.

[48] R. Thomas, Practical Guide to ICP-MS, Marcel Dekker, Inc., New York, 2004.

[49] H.E. Garbarino, J. R.; Taylor, Stable isotope dilution analysis of hydrologic samples by inductively coupled plasma mass spectrometry, Anal. Chem. 59 (1987) 1568-1575. 
doi:10.1021/ac00138a018.

[50] W. Doherty, An internal standardization procedure for the determination of yttrium and the rare earth elements in geological materials by inductively coupled plasma-mass spectrometry, Spectrochim. Acta. 44B (1989) 263-280. doi:10.1016/0584-8547(89)80031-X.

[51] Y. Igarashi, H. Kawamura, K. Shiraishi, Y. Takatu, Determination of thorium and uranium in biological samples by inductively coupled plasma mass spectrometry using internal standardisation, J. Anal. At. Spectrom. 4 (1989) 571-576.

Figure 1. Variation of ${ }^{238} \mathrm{U}$ sensitivity for different standard solutions over the measurement time (about 10 real seawater samples were measured following each standard solution; legends below the figure indicate the ${ }^{238} \mathrm{U}$ concentrations of the standard solutions; the numbers in the bracket are the date $(\mathrm{dd} / \mathrm{mm} / \mathrm{yy})$ for the ICP-MS measurement) 


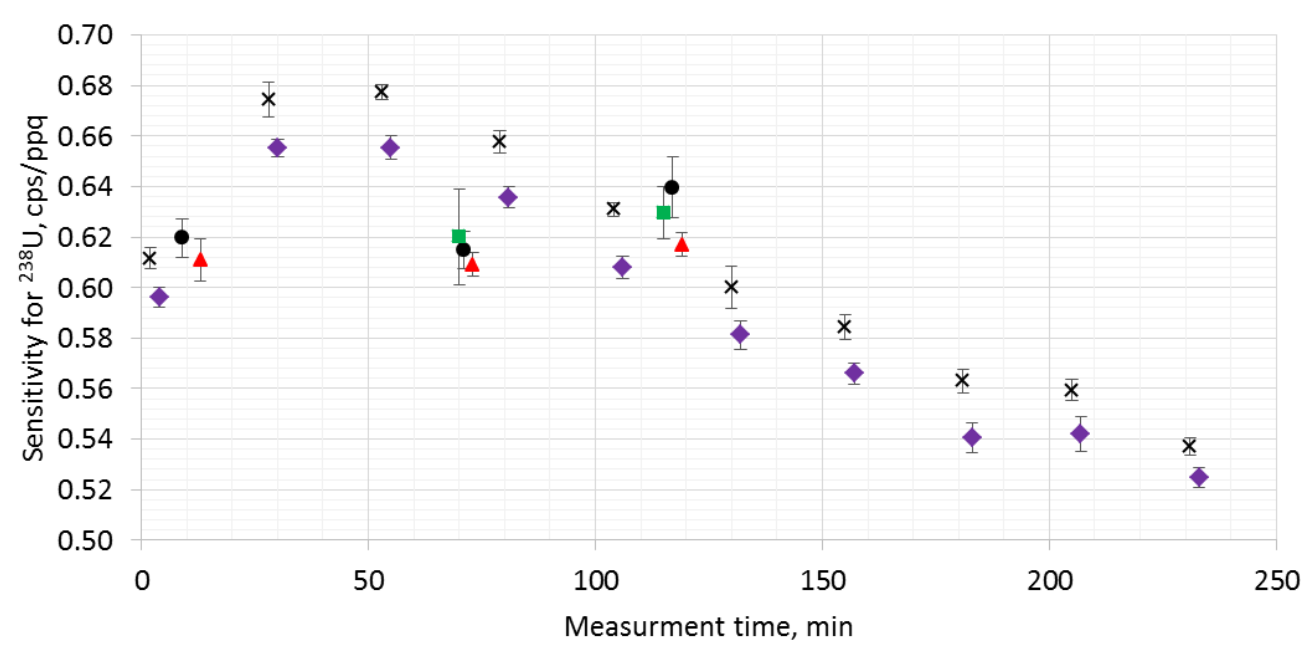

- $0.2 \mathrm{ppb}(1 / 5 / 16) \quad 0.1 \mathrm{ppb}(1 / 5 / 16) \quad \Delta 1 \mathrm{ppb}(1 / 5 / 16) \quad \times 0.1 \mathrm{ppb}(24 / 3 / 17) \quad 1 \mathrm{ppb}(24 / 3 / 17)$ 
Figure 2. Correlation between internal/external standardization (std. as abbreviation in the figure) and isotope dilution approaches for the quantitation of ${ }^{238} \mathrm{U}$ concentration in 50 timediluted real seawater samples $(n=112)$

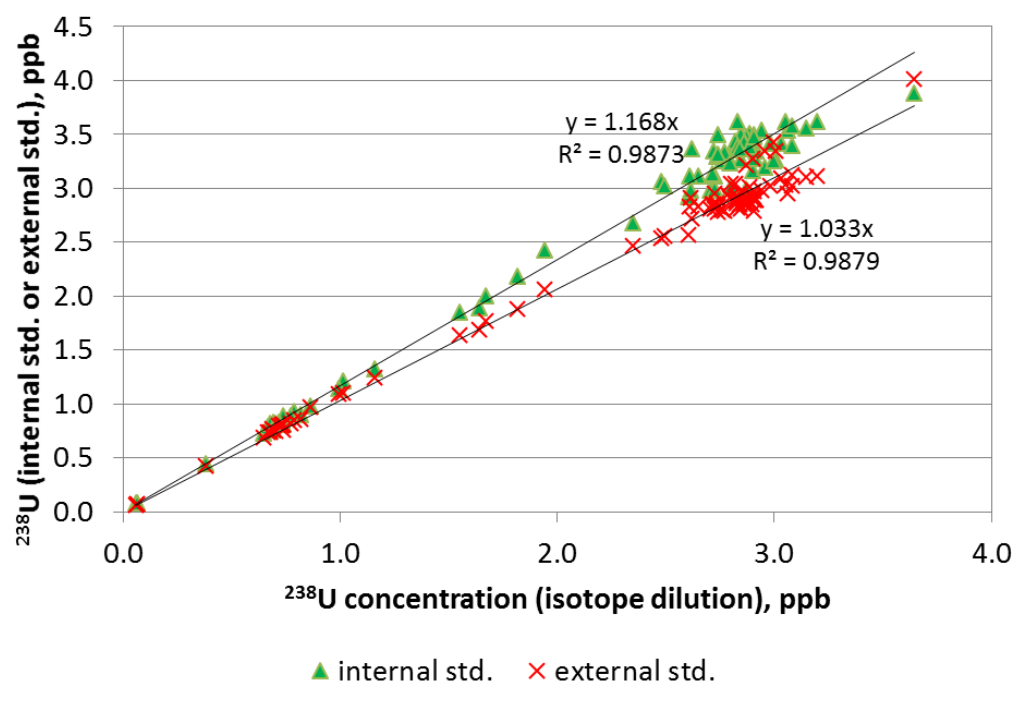


Figure 3. ${ }^{238} \mathrm{U}$ concentration and salinity measured for the subsamples taken at different depth from two bulk samples (Roskilde SWT and Greenland SWT, 600 L for each) stored for 6 months
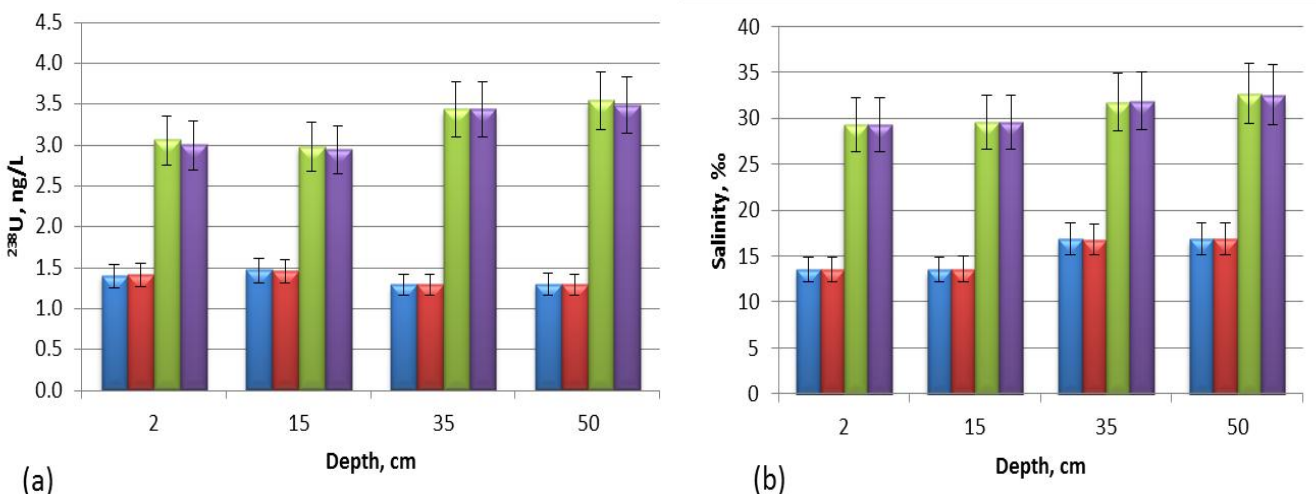

घRoskilde SWT-filtered $\square$ Roskilde SWT-unfiltered $\square$ Greenland SWT-filtered

घGreenland SWT-unfiltered

(a)

(b)

Table 1. ICP-QQQ operating conditions employed for the determination of ${ }^{238} \mathrm{U}$

\begin{tabular}{ll}
\hline Scan Type & $\begin{array}{l}\text { Single Quad } \\
\text { Nune mode }\end{array}$ \\
Acq Mode & $\begin{array}{l}\text { Spectrum } \\
\text { Q2 Peak Pattern }\end{array}$ \\
& 1 point \\
RF Power & $1550 \mathrm{~W}$ \\
RF Matching & $1.80 \mathrm{~V}$ \\
Smpl Depth & $6.4 \mathrm{~mm}$ \\
Carrier Gas Flow & $1.10 \mathrm{~L} / \mathrm{min}$ \\
Sweeps & 300 \\
Total Acq time/replicate [sec] & 12.36 \\
Monitored mass and Integrated & 1150.1 \\
time [sec] & 2320.1 \\
& 2333 \\
& 2383 \\
\hline
\end{tabular}




\begin{tabular}{l} 
Replicates \\
\hline
\end{tabular}

Table 2. Results for direct measurement of ${ }^{238} \mathrm{U}$ in IAEA-381 Irish seawater using different calibration approaches

\begin{tabular}{|c|c|c|c|c|c|c|c|}
\hline $\begin{array}{l}\text { Dilution } \\
\text { factor }\end{array}$ & $\begin{array}{c}\text { Subsampl } \\
\mathrm{e}^{\#}\end{array}$ & $\begin{array}{l}{ }^{238} \mathrm{U} \text {-isotopic } \\
\text { dilution } \\
\left.{ }^{(233} \mathrm{U}\right), \mathrm{ppb}\end{array}$ & $\begin{array}{c}\text { Bias*, } \\
\%\end{array}$ & $\begin{array}{c}{ }^{238} \mathrm{U} \text {-external } \\
\text { standardizatio } \\
\mathrm{n}, \mathrm{ppb}\end{array}$ & $\begin{array}{c}\text { Bias*, } \\
\%\end{array}$ & $\begin{array}{c}{ }^{238} \mathrm{U} \text {-internal } \\
\text { standardization } \\
\left({ }^{115} \mathrm{In}\right), \mathrm{ppb}\end{array}$ & $\begin{array}{c}\text { Bias*, } \\
\%\end{array}$ \\
\hline \multirow[t]{6}{*}{10} & A & $3.20 \pm 0.17$ & -5.5 & $2.17 \pm 0.22$ & -36.1 & $\mathrm{NM}$ & NM \\
\hline & B & $3.18 \pm 0.16$ & -6.2 & $2.20 \pm 0.22$ & -35.0 & NM & NM \\
\hline & $\mathrm{C}$ & $3.18 \pm 0.16$ & -6.1 & $2.39 \pm 0.24$ & -29.5 & NM & NM \\
\hline & D & $3.17 \pm 0.16$ & -6.5 & $2.43 \pm 0.24$ & -28.4 & NM & NM \\
\hline & E & $3.11 \pm 0.18$ & -8.3 & $2.31 \pm 0.23$ & -31.8 & $3.82 \pm 0.23$ & 12.7 \\
\hline & $\mathrm{F}$ & $3.13 \pm 0.17$ & -7.6 & $2.39 \pm 0.24$ & -29.6 & $3.58 \pm 0.20$ & 5.5 \\
\hline Average & & 3.16 & -6.7 & 2.31 & -31.7 & 3.70 & 9.1 \\
\hline SD & & 0.04 & & 0.11 & & 0.17 & \\
\hline \multirow[t]{6}{*}{20} & A & $3.27 \pm 0.18$ & -3.4 & $2.68 \pm 0.27$ & -20.8 & $\mathrm{NM}$ & NM \\
\hline & B & $3.35 \pm 0.17$ & -1.2 & $2.69 \pm 0.27$ & -20.6 & NM & NM \\
\hline & $\mathrm{C}$ & $3.28 \pm 0.18$ & -3.2 & $2.93 \pm 0.29$ & -13.5 & NM & NM \\
\hline & $\mathrm{D}$ & $3.30 \pm 0.17$ & -2.6 & $2.96 \pm 0.30$ & -12.7 & $\mathrm{NM}$ & NM \\
\hline & E & $3.28 \pm 0.18$ & -3.1 & $2.97 \pm 0.30$ & -12.5 & $3.34 \pm 0.18$ & -1.4 \\
\hline & $\mathrm{F}$ & $3.28 \pm 0.17$ & -3.2 & $3.00 \pm 0.30$ & -11.5 & $3.30 \pm 0.17$ & -2.5 \\
\hline Average & & 3.30 & -2.8 & 2.87 & -15.3 & $3.32 \pm$ & -2.0 \\
\hline SD & & 0.03 & & 0.14 & & 0.03 & \\
\hline \multirow[t]{6}{*}{50} & A & $3.56 \pm 0.19$ & 5.1 & $3.31 \pm 0.33$ & -2.4 & NM & NM \\
\hline & B & $3.60 \pm 0.19$ & 6.3 & $3.25 \pm 0.33$ & -4.3 & $\mathrm{NM}$ & NM \\
\hline & $\mathrm{C}$ & $3.37 \pm 0.24$ & -0.6 & $3.34 \pm 0.33$ & -1.6 & $3.85 \pm 0.22$ & 13.7 \\
\hline & D & $3.33 \pm 0.19$ & -1.7 & $3.36 \pm 0.34$ & -0.9 & $3.92 \pm 0.21$ & 15.6 \\
\hline & $\mathrm{E}$ & $3.60 \pm 0.18$ & 6.2 & $3.74 \pm 0.37$ & 10.3 & $3.47 \pm 0.18$ & 2.2 \\
\hline & $\mathrm{F}$ & $3.63 \pm 0.19$ & 7.0 & $3.67 \pm 0.37$ & 8.3 & $3.55 \pm 0.18$ & 4.6 \\
\hline Average & & 3.52 & 3.7 & 3.44 & 1.6 & 3.70 & 9.0 \\
\hline SD & & 0.13 & & 0.21 & & 0.22 & \\
\hline
\end{tabular}

\# Each subsample was prepared and measured by independently.

*The information value of ${ }^{238} \mathrm{U}$ in IAEA-381 Irish seawater is $3.39 \pm 0.32 \mathrm{ppb}$ [47].

'NM' means the replicate was not measured using the internal standardization approach.

All the uncertainties for ${ }^{238} \mathrm{U}$ concentrations are the expanded uncertainties with a coverage factor of $\mathrm{k}=1$. 


\section{Highlight}

- A rapid and simple method for direct measurement of ${ }^{238} \mathrm{U}$ in seawater was established based on the use of triple quadrupole inductively coupled mass spectrometry (ICP-QQQ).

- 20-50 time dilution for typical seawater samples combining with isotope dilution for quantitation analysis is recommended in the proposed method for achieving reliable ${ }^{238} \mathrm{U}$ measurement.

- A 'differentiation' phenomenon in ${ }^{238} \mathrm{U}$ concentration was observed for the first time in subsamples taken from different layers of long-term stored bulk seawater (600 L), indicating that the sample representativeness is important to be bear in mind especially when handling large volume water samples after long periods of storage. 